\title{
X-Ray Diffraction Technique Applied to Study of Residual Stresses after Welding of Duplex Stainless Steel Plates
}

\author{
Vladimir Ivanovitch Monin ${ }^{\mathrm{a}}$, Ricardo Tadeu Lopes ${ }^{\mathrm{b}}$, Sergio Nolêto Turibus ${ }^{\mathrm{b} *}$, \\ João C. Payão Filho ${ }^{\mathrm{b}}$,Joaquim Teixeira de Assis ${ }^{\mathrm{a}}$ \\ anstituto Politécnico do Rio de Janeiro - IPRJ, Universidade do Estado do Rio de Janeiro - UERJ, \\ CP 97282, CEP 28610-974, Nova Friburgo, RJ, Brasil \\ ${ }^{\mathrm{b}}$ Universidade Federal do Rio de Janeiro - UFRJ, \\ CP 68509, CEP 21941-972, Rio de Janeiro, RJ, Brasil
}

Received: June 24, 2013; Revised: January 15, 2014

\begin{abstract}
Duplex stainless steel is an example of composite material with approximately equal amounts of austenite and ferrite phases. Difference of physical and mechanical properties of component is additional factor that contributes appearance of residual stresses after welding of duplex steel plates. Measurements of stress distributions in weld region were made by X-ray diffraction method both in ferrite and austenite phases. Duplex Steel plates were joined by GTAW (Gas Tungsten Arc Welding) technology. There were studied longitudinal and transverse stress components in welded butt joint, in heat affected zone (HAZ) and in points of base metal $10 \mathrm{~mm}$ from the weld. Residual stresses measured in duplex steel plates jointed by welding are caused by temperature gradients between weld zone and base metal and by difference of thermal expansion coefficients of ferrite and austenite phases. Proposed analytical model allows evaluating of residual stress distribution over the cross section in the weld region.
\end{abstract}

Keywords: duplex steel, welding, X-ray diffraction, residual stresses

\section{Introduction}

Welding is generally the simplest, fastest, and most cost-effective technological process widely used in various industries and engineering fields such as shipbuilding, pipeline construction, offshore oil, gas production and others. Different physical metallurgical processes that occur during welding induce appearance of significant residual stresses that may have considerable influence on service behavior of welded structures and components, to cause even failures of welded joints. Origin and sources of residual stresses after welding were studied in ${ }^{1-3}$. In the case of welding of materials with heterogeneous microstructure, like biphasic duplex stainless steel (DSS), the residual stress state formation depends also on difference between physical mechanical properties of components of heterogeneous material ${ }^{4-6}$.

There are many methods of residual stress measurements but one of the important is the X-ray diffraction method that permits to carry out detail analysis of residual stress state in weld region. X-ray tensometry applied to study of duplex stainless steels allows measuring of stresses both in ferrite and austenite phases. There are numerous examples of stress measurements by X-ray diffraction method, but sometimes they contain contradictory results.

The objective of the present paper is to analyze residual stress state in ferritic and austenitie phases arising after

*e-mail: sturibus@nuclear.ufrj.br welding of two DSS plates by GTAW (Gas Tungsten Arc Welding) technology. X-ray diffraction method known as " $\sin ^{2} \psi-$ method" was used to study the longitudinal and transverse stress components in welded butt joint, in heat affected zone (HAZ) and in points of base metal $10 \mathrm{~mm}$ from the weld. To explain the experimental results it was proposed the analytical model permitting to evaluate the distribution of residual stress in components of DSS over cross section of the weld.

\section{Methodology}

\section{1. $\operatorname{Sin}^{2} \psi-$ method of $X$-ray tensometry}

The methodology of stress measurements by X-ray diffraction technique is based on equation of theory of elasticity for deformation in arbitrary direction?

$\varepsilon_{\varphi, \psi}=\frac{1+v}{E} \sigma_{\varphi} \sin ^{2} \psi-\frac{v}{E}\left(\sigma_{1}+\sigma_{2}\right)$

Where E, $\nu$ are elastic constants, $\varphi$ and $\psi$ are azimuthal and polar angles in spherical coordinate system, $\sigma \varphi$ are measured stress component in the $\varphi$-direction, $\sigma_{1}$ and $\sigma_{2}$ are principal stresses. Figure 1 illustrates stress and strain components on the surface of analyzed material.

In terms of diffraction experiment this equation can be expressed as: 
$\varepsilon_{\varphi, \psi}=\frac{d_{\varphi, \psi}-d_{0}}{d_{0}}=-\operatorname{ctg}\left(\theta_{\varphi, \psi}-\theta_{\psi=0}\right)$

Where $d \varphi \psi, d_{0}, \theta \varphi \psi, \theta_{0}$ are the interplanar distances and diffraction angles for analyzed and unstressed material, respectively. From above equations it can be obtained expression for diffraction angle $\theta \varphi \psi$ :

$\theta_{\varphi, \psi}=\theta_{0}-\frac{1+v}{E} \frac{\sigma}{\operatorname{ctg} \theta_{0}} \sin ^{2} \psi+\frac{v}{E} \frac{\left(\sigma_{1}+\sigma_{2}\right)}{\operatorname{ctg} \theta_{0}}$

It can be seen that $\theta \varphi \psi_{=} f\left(\sin ^{2} \psi\right)$ is linear function. From the slope of this function follows the formula for stress calculation:

$\sigma_{\varphi, \psi}=\frac{E}{1+\nu} \operatorname{ctg}\left(\theta_{\psi=90}-\theta_{\psi=0}\right)$

Where $\left(\theta_{\psi=90}-\theta_{\psi=0}\right)$ is tangent of the slope angle.

Substituting values of elastic constants and known parameters in Equation 4 we obtain formulas for stress calculation in ferrite and austenite phases:

1. For ferrite phase $\sigma_{\varphi}=-2,14\left(\theta_{\psi=90}-\theta_{\psi=0}\right)$ with absolute error $\Delta \sigma= \pm 15 \mathrm{MPa}$;

2. For austenite phase $\sigma_{\varphi}=-4,56\left(\theta_{\psi=90}-\theta_{\psi=0}\right)$ with absolute error $\Delta \sigma= \pm 25 \mathrm{MPa}$;

Thus, diffraction angles determined from diffraction experiment are the main parameters of X-ray tensometry.

\section{Results and Discussion}

\subsection{Experimental procedure and stress measurements}

Plates for welding were prepared from duplex stainless steel grade 2205 of Sandmeyer Steel Co. Chemical composition of this steel is shown in Table 1.

Figure 2 shows geometry of weld joints and dimensions of plates prepared for welding.

Joint of two duplex steel plates was made by GTAW (Gas Tungsten Arc Welding) technology. It was made by 20 alternating steps. Before next welding step plate was cooled to $60^{\circ} \mathrm{C}-80^{\circ} \mathrm{C}$. Plates after welding are shown in Figure 3 . It can be seen significant distortion of welded plates.

Figure 3 shows the points where measurements of longitudinal (along of weld) and transverse (perpendicular to weld) stress components were made. Point P1 is located in the center of weld, P2 is in HAZ (heat affected zone), P3 and $\mathrm{P} 4$ are in base metal $5 \mathrm{~mm}$ and $10 \mathrm{~mm}$ distant from the border of the weld, respectively.

Diffraction experiments were carried out with using of portable X-ray apparatus with position sensitive detector. $\mathrm{Cr}-\mathrm{K} \alpha$ radiation and reflections (211) for ferrite and (220) for austenite provide precisions 15 MPA for ferrite phase and $30 \mathrm{MPa}$ for austenite.

The results of measurements longitudinal and transverse components are shown in Table 2.

\subsection{Discussion}

Experimental results presented in Table 2 show that residual stress state in weld region is characterized by tensile stresses both in ferrite and austenite phases decreasing in

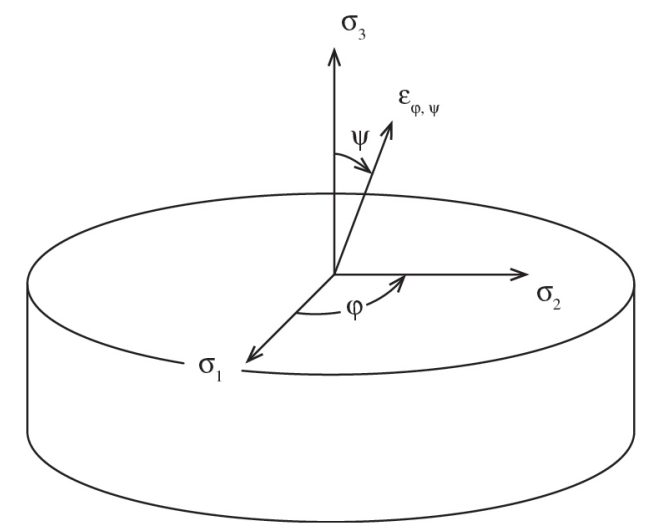

Figure 1. Strain component $\varepsilon \varphi, \psi$ on the surface of material.

Table 1. Chemical Composition of Duplex Steel 2205.

\begin{tabular}{cccccc}
\hline \multicolumn{6}{c}{ Typical values (weight \%) } \\
\hline $\mathbf{C}$ & $\mathbf{C r}$ & $\mathbf{N i}$ & $\mathbf{M o}$ & $\mathbf{N}$ & Other \\
\hline $0.02 \%$ & $22.10 \%$ & $5.60 \%$ & $3.10 \%$ & $0.18 \%$ & $\mathrm{~S}=0.001 \%$ \\
& $\mathrm{PREN}=[\mathrm{Cr} \%]+3.3[\mathrm{Mo} \%]+16[\mathrm{~N} \%] \geq 34$ \\
\hline
\end{tabular}

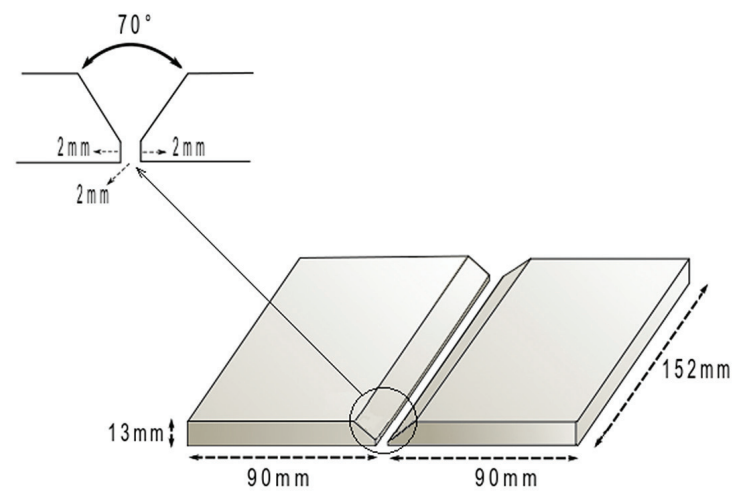

Figure 2. Geometry of weld joint and dimensions of plates for welding.

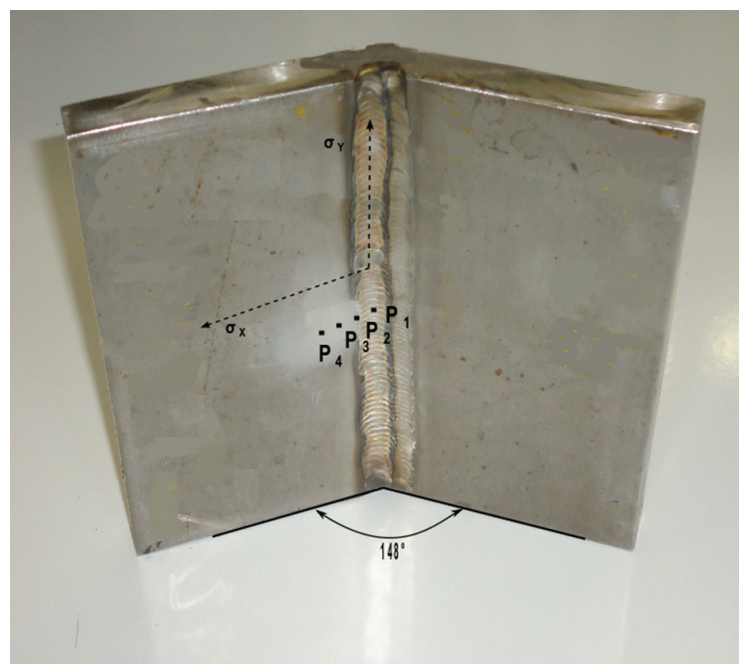

Figure 3. Duplex steel plates after GTAW welding. 
heat affected zone and becoming small compressive in base metal. At the same time longitudinal residual stresses in the weld zone are higher than transverse stresses. This character of weld residual stresses may indicate that on the one hand the shrinkage process during cooling of weld zone is principal cause of their arising and on the other hand that weld thermal contraction is not uniform. It is restrained along the weld seam and unrestrained in perpendicular direction.

The difference between residual stresses in ferrite and austenite phases is associated with different coefficients of thermal expansion of these components. Small value of austenite residual stresses in weld zone may be explained by plastic deformation this component caused by high thermal stresses accompanying of cooling process of weld region.

\subsection{Formation of residual stress state due to welding process}

Analytical evaluation of distribution of residual stresses is based on the analysis of equilibrium conditions. For the transverse and longitudinal stresses which arise after welding the equilibrium conditions can be interpreted as equality to zero the resultants of forces and moments generated by these stresses in perpendicular cross-sectional. Figure 4 shows sections of imaginary cutting for analysis of equilibrium conditions for longitudinal and transverse stresses arising in the weld region.

For longitudinal stresses equality to zero of resultants confirms by the symmetry of the plates with respect to the

Table 2. Distribution of transverse and longitudinal residual stresses.

\begin{tabular}{ccccc}
\hline \multirow{2}{*}{ Points } & \multicolumn{3}{c}{ Measured stress (MPa) } \\
\cline { 2 - 5 } & \multicolumn{2}{c}{ Longitudinal } & \multicolumn{2}{c}{ Transverse } \\
\cline { 2 - 5 } & Ferrite & Austenite & Ferrite & Austenite \\
\hline P1 & 770 & 470 & 220 & 110 \\
P2 & 210 & 470 & 150 & 210 \\
P3 & -120 & -201 & -180 & -200 \\
P4 & -150 & -100 & -100 & -130 \\
\hline
\end{tabular}

weld bead (section A-A in Figure 4a). Thus, equality to zero of the forces resultant can be written as:

$$
\begin{gathered}
\int_{A_{\text {chapas }}} \sigma_{\text {plate }} d A+\int_{A_{\text {cordão }}} \sigma_{\text {weld }} d A=0 \\
\sigma_{\text {plate }}^{\text {average }} * A_{\text {plate }}=-\sigma_{\text {weld }}^{\text {average }} * A_{\text {weld }}
\end{gathered}
$$

Where $\sigma_{\text {plate }}^{\text {average }}, \sigma_{\text {weld }}^{\text {average }}, \mathrm{A}_{\text {plate }}, \mathrm{A}_{\text {weld }}$ are the average stresees and areas of plate and weld bead, respectively.

For transverse stresses the sections (B-B) and (C-C) pass through the weld bead or the base metal. Therefore, any transverse stress component on the surface of the weld or base metal has to be balanced by the opposite inside of these parts of welded plates. This means that stress distribution of transverse residual stresses over cross-section is heterogeneous and heterogeneity is formed and alternated during each step of welding.

The formation of transverse stresses and evaluation of stress distribution in depth of the weld can be made by analysis of contractions and deformations of the layers of metal after each step of welding. Figure 5 shows distortion of joint duplex steel plates after the first two steps of welding caused by contractions.

At the end of the second step of welding the temperature of this layer is hotter than the metal of the first step. The contraction of hot metal during cooling creates the tensile thermal stress in this layer (Figure 6a). Yield stress of hot metal is low so the second layer deforms plastically by thermal stress until the temperature when thermal stress becomes equal to yield stress. This part of cooling is not accompanied by distortion of joint plates (Figure 6b). Continuing cooling of second layer causes distortion of joint plates as it shown in Figure 6c. This distortion process initiates the appearance of residual stresses increasing until state when temperatures of these layers become equal. Details of deformations during cooling and formation of residual stress state caused by distortions are shown in Figure 6.

Analytical determination of residual stresses is based on comparing of displacements of hot and cold layers of welded metal. If the temperature difference between hot and cold

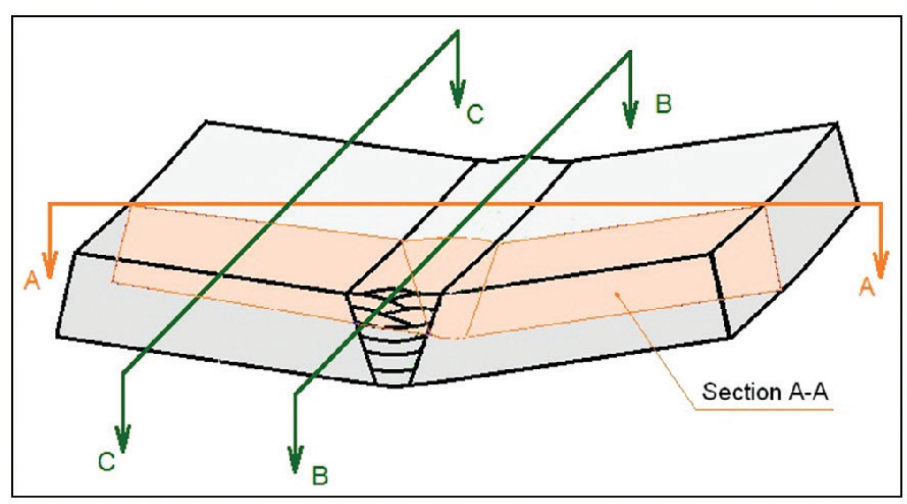

(a)

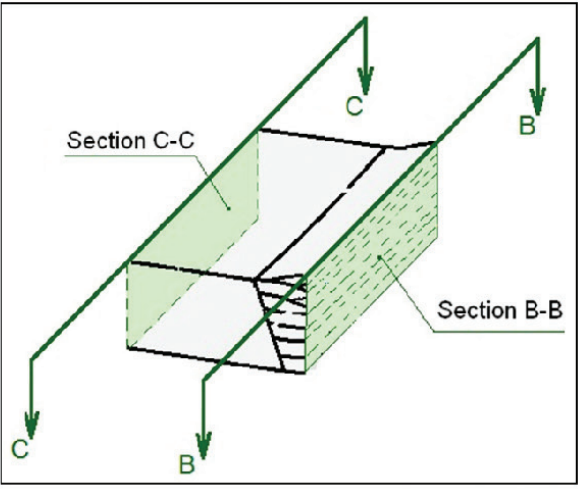

(b)

Figure 4. Cross sections of welded plates for analysis of equilibrium conditions. 


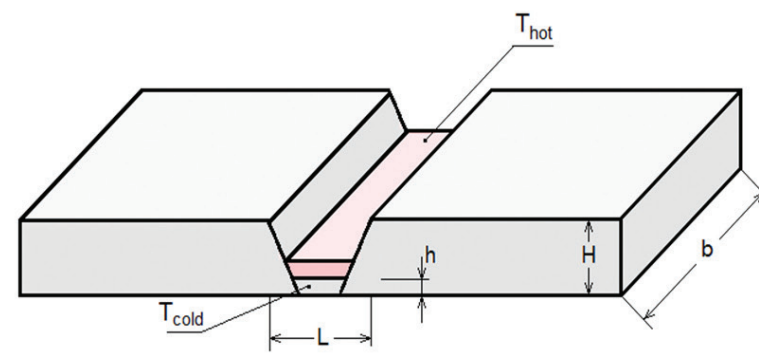

(a)

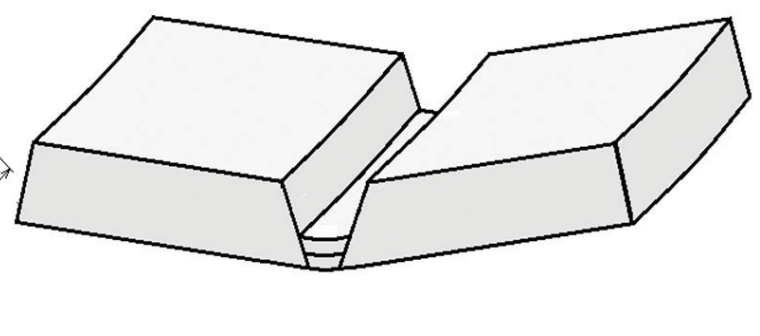

(b)

Figure 5. The scheme of distortion of welded plates caused by contraction of the weld metal: a - initial state; b real distorted state; $\mathrm{T}_{\text {cold }}$ - temperature of cold metal after first step of welding; $\mathrm{T}_{\text {hot }}$ - temperature of hot metal at the time of second step of welding.

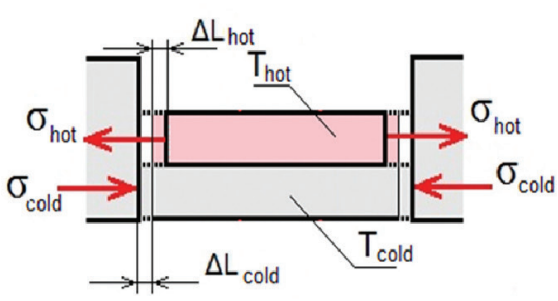

(a)

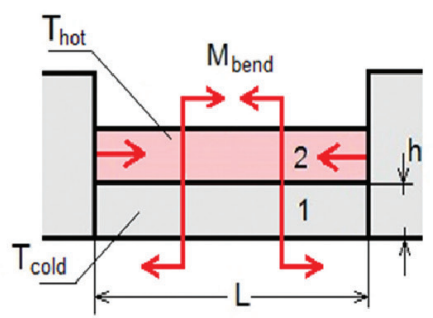

(b)

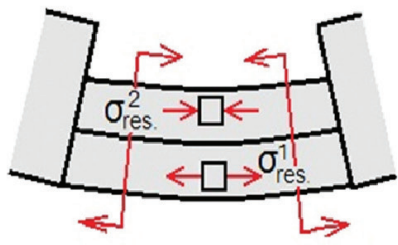

(c)

Figure 6. Arising of internal forces and moments in the layers of metal after two steps of welding.

layers is $\Delta \mathrm{T}=\mathrm{T}_{\text {hot }}-\mathrm{T}_{\text {cold }}$ (Figure 6a) then the contraction of the hot layer can be expressed as:

$\Delta \mathrm{L}=\alpha^{*} \Delta \mathrm{T}^{*} \mathrm{~L}$

Where $\alpha$ is the thermal expansion coefficient of duplex steel, $\mathrm{L}$ is length of the layers. The integrity of the layers 1 and 2 is realized by elongation $\Delta \mathrm{L}_{\text {hot. }}$ of layer 2 and contraction $\Delta \mathrm{L}_{\text {cold }}$ of layer 1 caused by stresses $\sigma_{\text {hot }}$ and $\sigma_{\text {cold }}$ (Figure 6a). Therefore:

$\Delta \mathrm{L}=\left|\Delta \mathrm{L}_{\text {hot }}\right|+\left|\Delta \mathrm{L}_{\text {cold }}\right|$

The displacements $\Delta \mathrm{L}_{\text {hot }}$ and $\Delta \mathrm{L}_{\text {cold. }}$ can be determined by:

$\Delta \mathrm{L}_{\mathrm{hot}=} \mathrm{L}^{*} \sigma_{\mathrm{hot}} / \mathrm{E}$

$\Delta \mathrm{L}_{\text {cool }}=\mathrm{L}^{*} \sigma_{\text {cold }} / \mathrm{E}$

Where E is Young's modulus of duplex steel. After substitution of corresponding expressions Equation 8 can be written as:

$\alpha * \Delta \mathrm{T}^{*} \mathrm{E}=\sigma_{\text {hot }+} \sigma_{\text {cold }}$

For equal thicknesses of layers 1 and 2 the stresses $\sigma_{\text {hot }}$ and $\sigma_{\text {cold }}$ are equal too, and then residual stress caused by shrinkage can be calculated as:

$\sigma_{\text {res }}^{*}=0,5 \alpha \cdot \Delta \mathrm{T}^{*} \mathrm{E}$
Since thermal expansion coefficient of duplex steel is $\alpha=13.7 \times 10-61 / \mathrm{C}^{\circ}$ and Young's modulus $\mathrm{E}=2 \times 105 \mathrm{MPa}^{6[8]}$ Equation 12 can be written as:

$\sigma_{r e s}^{*}=1,37 * \Delta \mathrm{T}$

For temperature difference of layers iqual to $200{ }^{\circ} \mathrm{C}$ or $300{ }^{\circ} \mathrm{C}$ the value of residual stress varies from 274 to $410 \mathrm{MPa}$. The diagram of this initial stress state over cross section of weld is shown in Figure 6b.

The contraction of the metal layer in the second step also creates a bending moment $\mathbf{M}_{\text {bend }}$

$\mathrm{M}_{\text {bend }}=\sigma_{\text {res }} \cdot(\mathrm{hb}) \cdot \mathrm{h}$

Thus, the second component residual stress $\sigma_{\text {res }}^{* *}$ caused by pure bending can be determined as:

$\sigma_{\text {res. }}^{* *}(z)=\frac{M_{\text {flex. }} z}{I_{x}}$

Where $z$ is the coordinate along the thickness of the weld bead and $I_{x}$ is the moment of inertia. For rectangular section with sides b, h (Figure 5a) $I_{x}$ is equal to:

$I_{x}=\frac{b(2 \mathrm{~h})^{3}}{12}$

After simplifying of Equation 15, for $\mathrm{z}=\mathrm{h}$ we can write:

$\sigma_{\text {res. }}^{* *}(z)=\frac{\sigma_{\text {res. }} .4 \mathrm{z}}{3 \mathrm{~h}}=\frac{4}{3} \sigma_{\text {res }}^{*}$

The sum of the components residual stresses given by the Equations 13 and 17 forms the real residual stress: 


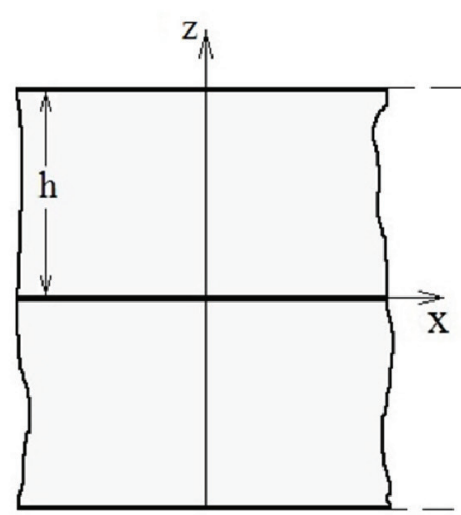

(a)

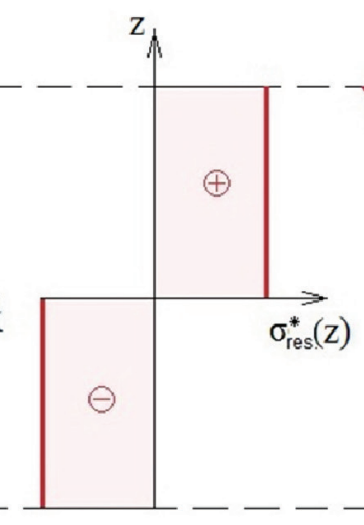

(b)

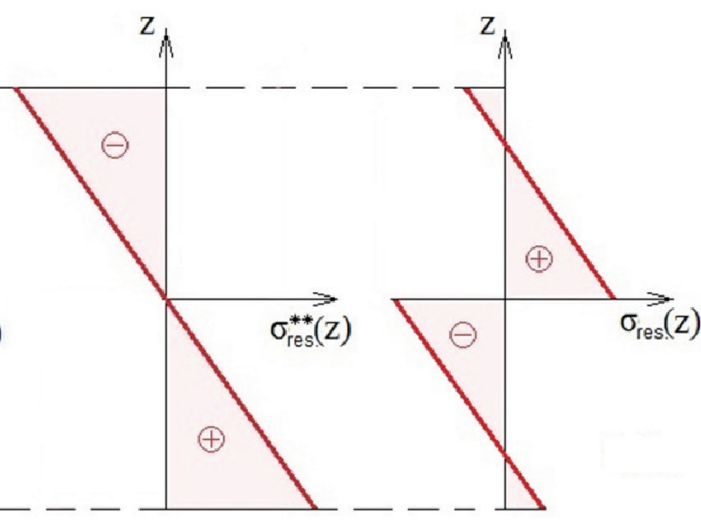

(c)

(d)

Figure 7. Formation of residual stresses in layers of metal after two steps of welding: a - cross section of two layers of weld metal: b, c, d - diagrams of residual stresses distribution.

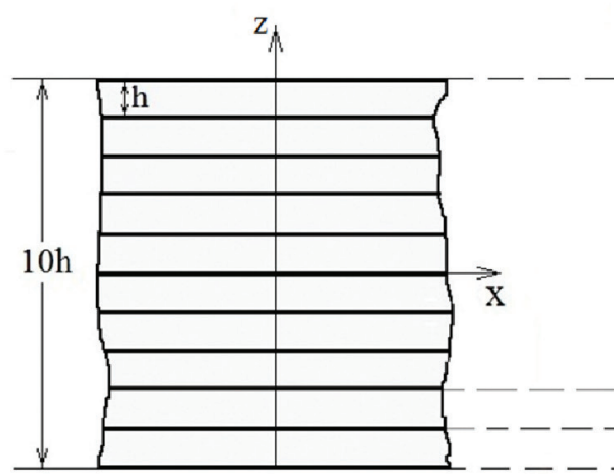

(a)

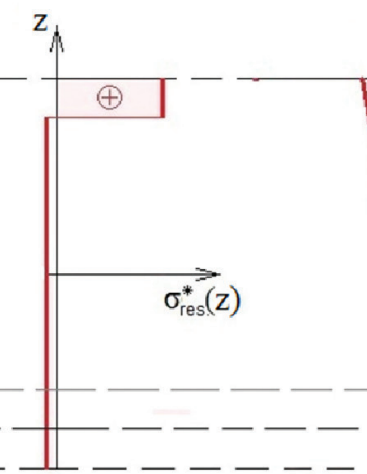

(b)

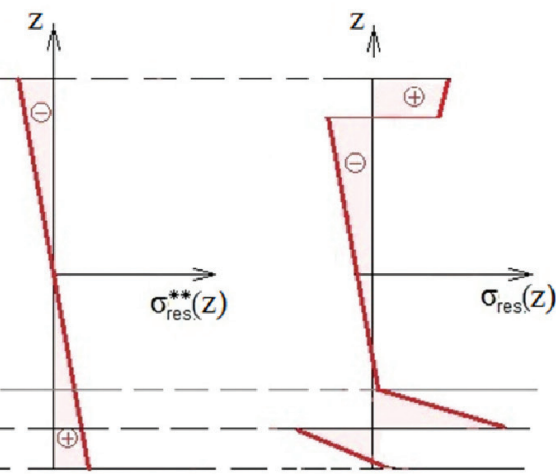

(c)

(d)

Figure 8. Formation of residual stresses after 10 weld steps: a - cross section of 10 layers; b, c, d - diagrams of residual stress distribution.

$\sigma_{\text {res. }}(z)=\sigma_{\text {res }}^{*}(z)+\sigma_{\text {res. }}^{* *}(z)$

The distribution of residual stresses $\sigma_{\text {res. }}(\mathrm{z})$ along the thickness of the weld bead is shown in Figure 7d.

Is demonstrated that the residual stress distribution (Figure 7d) is balanced both the resultant of forces and resultant of moments.

The mechanism of formation of residual stresses after following weld steps is the same. Figure 8 shows the diagrams of residual stress distribution after 10 weld steps.

Analyzing residual stresses components $\sigma_{\text {res }}$ determined by Equation 12 shown in Figure 8b, we can see that stress value in cool layers decreases after new steps. Residual stresses $\sigma_{\text {res. }}$ determined by Equation 15 and shown in Figure $7 \mathrm{c}$ also decreases. The diagram $8 \mathrm{~d}$ is modified by the action of the first two steps shown in Figure 8d.

Applying this mechanism to duplex stainless steel we can note that austenite phase due to its plasticity is subjected to low residual stress than ferrite phase. Character of stress distributions in ferrite and austenite phases is same.

Stress distribution presented in Figure 8 by diagram $8 \mathrm{~d}$ is related to transverse residual stresses. Distribution of longitudinal stresses is more homogeneous because it caused by shrinkage of weld bead and can be evaluated by Equation 13. Its value is more than transverse residual stress. Experimental measurements of longitudinal and transverse residual stresses presented in Table 2 agree with this conclusion.

\section{Conclusions}

- It has been shown that residual stress state in weld seam is characterized by tensile stresses both in ferrite and austenite phases. This fact confirms that arising of these residual stresses is caused by shrinkage process during cooling of weld zone;

- High level of longitudinal than transverse residual stresses is explained by restrained and unrestrained cooling in directions along and perpendicular to weld seam respectively;

- It has been shown that distribution of transverse residual stresses over cross section of weld seam has to be inhomogeneous in contrast to longitudinal stress distribution that is more homogeneous. It has been proposed physical model explaining distribution of transverse residual stresses arising after welding;

- Lower level of residual stresses in austenite than ferrite phase of duplex stainless steel is due to larger plastic deformation of austenite. 


\section{References}

1. Macherauch E and Wolfahrt H. Different Sources of Residual Stresses as a Result of Welding. Residual Stresses in welding Constructions and their Effects, Welding Institute Reprint; 1977. p. 267-282.

2. Hauk V. Structural and Residual Stress Analysis by Nondestructive Methods. Evaluation, Application, Assessment. Amsterdam: Elsevier; 1997.

3. Pfeiffer W. Residual stress in heavy wall weldments. In: International Symposium "Safety in Aplication of High Strength Steel"; 1997; Trondheim. Trondheim; 1997.

4. Mcirdi L, Inal K and Lebrun JL. Analysis by X-ray diffraction of the mechanical behaviour of austenitic and ferritic phases of a duplex stainless steel. Advances in X-ray Analysis. 2000; 42:397-406.
5. Dakhlaoui R and Braham C, Baczmánski A Mechanical properties of phases in austeno-ferritic duplex stainless steel-Surface stresses studied by X-ray diffraction. Materials Science and Engineering A. 2007; 444:6-17. http://dx.doi. org/10.1016/j.msea.2006.06.074

6. Baczmánski A, Braham C and Seiler W. Evolution of plastic incompatibility stresses in duplex stainless steel determined by X-ray diffraction. Physica Status Solidi A-Applied Research. 2005; 195(13):2886-2899. http://dx.doi.org/10.1002/ pssa. 200306848

7. Timoshenko SP and Goodier NJ. Theory of Elasticity. New York: McGraw-Hill; 1980.

8. Atlas Specialty Metals. Technical Handbook of Stainless Steels. Available from: <www.atlasmetals.com.au $>$. 